\title{
Um Estudo de Impacto Ambiental Utilizando Análises Estatísticas Espacial e Multivariada
}

\section{${ }^{1}$ José Vicente E. Bernardi; ${ }^{2}$ Harold G. Fowler; ${ }^{3}$ Paulo M. Barbosa Landim}

\section{${ }^{1}$ Doutorando no Curso de Pós-Graduação em Geociências, Área "Geociências e Meio Ambiente" IGCE/UNESP, Rio Claro.}

\author{
${ }^{2}$ Departamento de Ecologia - IB/UNESP, Rio Claro.
}

${ }^{3}$ Departamento de Geologia Aplicada - IGCE/UNESP, Rio Claro.

\section{RESUMO}

A avaliação do impacto causado em um corpo de água receptor é de grande interesse para o entendimento das mudanças ocasionadas nos fatores ambientais que controlam a dinâmica dos ecossistemas aquáticos. $\mathrm{O}$ controle dos agentes poluidores pelos órgãos competentes é feito pontualmente sobre as concentrações de determinadas substâncias e apenas nas entradas dos efluentes, junto aos corpos receptores, não considerando a pluma do efluente, tornando-se necessário o monitoramento desse impacto em termos de distribuição espacial.

O objetivo deste estudo foi verificar o impacto da emissão de um efluente no Rio Paraíba do Sul, nas cercanias de Pindamonhangaba (SP), utilizando a análise de superfícies de tendência, por regressão polinomial, alem da análise estatística multivariada das componentes principais. As variáveis enfocadas foram: riqueza de gêneros do plâncton, $\mathrm{pH}$, temperatura, oxigênio dissolvido, transparência da água, cor e a turbidez da água.

A análise de superfície de tendências conseguiu auxiliar na interpretação do movimento da pluma do efluente no corpo receptor, podendo ser usada como base para um possível monitoramento. Os valores de resíduos da superfície polinomial de primeiro grau mostraram as diferenças locais existentes entre as margens e o meio do rio e ainda a nítida interferência do efluente na riqueza de gêneros do plâncton.

A análise das componentes principais forneceu como variáveis mais 
importantes DBO, OD, transparência da água, cor e numero de gêneros do plâncton, separando duas componentes principais: a primeira, mais importante e denominada abiótica, controlada por fatores físico-químicos e a segundo biológica, controlada pela riqueza de gêneros planctônicos. Os scores plotados em superfícies espaciais mostraram o impacto do efluente com relação às variáveis estudadas e recuperação das águas do rio ao final da malha de amostragem.

Palavras chaves: impacto ambiental, análise de superfícies de tendência, análise das componentes principais, Rio Paraíba do Sul (Brasil).

\section{ABSTRACT}

Evaluation of the impact caused by an effluent in a river is needed to understand the changes caused in the environmental factors that control the dynamics of the aquatic ecosystems. Pollutant agents control is punctual and made just in the entrances of the effluent, close to the receiving bodies, and the plume isn't considered. However, to monitoring this impact, is necessary to know its space distribution.

The purpose of this study was to verify the impact of the emission of an effluent in Paraíba do Sul River, near Pindamonhangaba, São Paulo State/Brazil, applying trend surface analysis and principal component analysis. The focused variables were: plankton genera, $\mathrm{pH}$, temperature, dissolved oxygen, water transparency, color and water turbidity.

Trend surface analysis helped understand the origin of the movements of the effluent plume on the receiving river that could be used as base for a possible monitoring. Residual values from the first-degree polynomial surface showed local differences between the margins and the middle of the river and the control of the effluent in number of the plankton genera.

The Principal Component Analysis indicated the most important variables like: DBO, OD, transparency of the water, color and number of plankton genera. The two main components are: the first, and more important, denominated abiotic, controlled by physical-chemical factors and a second, biological, controlled by plankton genera. The plotted scores in space surfaces showed the impact of the effluent with relationship to the studied variables and the reclamation in the river water at the end of the sampling grid.

Key words: environmental impact, trend surface analysis, principal component analysis, Paraíba do Sul River (Brazil). 
Os distúrbios provocados pelas dioxinas originárias da fabricação de celulose e papel são um importante determinante na estrutura e função dos ecossistemas aquáticos e isto é particularmente verdadeiro em ecossistemas fluviais onde as águas correntes encontram-se freqüentemente expostas a alterações naturais, como enchentes, e antropogênicas, como poluição química e orgânica (STEINMAN et al. 1992). O controle destes agentes poluidores, pelos órgãos competentes, é feito sobre as concentrações de determinadas substâncias consideradas por legislação específica, como o Decreto Federal No 24.643 de 1934 ou a lei No 1283, de 1950, que estabelece vários padrões de águas residuais (MURGEL-BRANCO, 1974). O controle é feito, porem, geralmente em termos pontuais e apenas nas entradas dos efluentes, junto aos corpos receptores, e não cobrindo a pluma toda do efluente.

Para a avaliação do impacto causado em um corpo de água receptor, de grande interesse para o entendimento das mudanças ocasionadas nos fatores ambientais que controlam a dinâmica dos ecossistemas aquáticos, torna-se necessário, porém, o uso de técnicas de análise espacial. Nesse sentido a análise de superfícies de tendência, por regressão polinomial, pode ser uma ferramenta muito útil para estes casos, pois alem de apresentar tendências de âmbito regional são capazes de ressaltar anomalias, positivas e negativas, localizadas. Considerando a escala espacial em que os fenômenos ecológicos ocorrem, as relações encontradas na natureza são gradativas (Legendre, 1993), significando que quanto mais próximos estiverem os pontos de coleta de uma determinada variável no espaço mais semelhantes entre si serão os valores obtidos. Desta forma, se o valor de uma variável, assumida em uma determinada localidade, puder ser pelo menos parcialmente previsto por valores em pontos vizinhos, estes valores serão dependentes um do outro. Além disso, em estudos de impacto ambiental consideram-se simultaneamente diversas variáveis para diagnóstico, sendo necessário técnicas estatísticas multivariadas que permitam um estudo conjunto dos fatores ambientais que controlam as mudanças ocasionadas. Devido à complexidade presente torna-se necessário o uso dessas técnicas para permitir inferências a respeito da importância das variáveis atuantes, que resulta numa redução nos custos e, também, orienta futuros estudos sobre as variáveis que realmente causam modificações. Entre essas técnicas pode ser citada a análise das componentes principais que facilita a interpretação da estrutura de um conjunto de dados multivariados a partir das respectivas matrizes de variâncias e covariâncias e/ou correlações.

Assim o objetivo deste estudo foi verificar o impacto causado pela emissão de um efluente no Rio Paraíba do Sul, nas cercanias de Pindamonhangaba (SP), utilizando a técnica estatística espacial da análise de superfície de tendências, alem da análise multivariada das componentes principais. Desse modo foi possível diagnosticar as distribuições espaciais das variáveis, sua importância e a magnitude do impacto causado na comunidade planctônica, necessária ao monitoramento desse efluente em termos da distribuição espacial dos fatores ambientais (físico-químicos e biológicos), ao estudo da autodepuração e da sucessão de populações de microorganismos, todos de grande 
importância para o entendimento e controle dos impactos causados no corpo receptor.

\section{MATERIAL E MÉTODOS}

O material para este estudo foi coletado, no mês de janeiro de 1993, no rio Paraíba do Sul, na fazenda Coruputuba, município de Pindamonhangaba, Estado de São Paulo, Brasil. A área estudada, com $2.900 \mathrm{~m}$ de comprimento por $100 \mathrm{~m}$ de largura, corresponde à fase meandrante do rio, porem retificado no trecho estudado. Foram coletados 90 pontos distribuídos, em malha regular, com intervalos ao longo da coordenada "X", paralela ao leito do rio, de $100 \mathrm{~m}$ e ao longo da coordenada "Y", perpendicular ao canal, com intervalos de $50 \mathrm{~m}$ a partir da margem direita $(0 \mathrm{~m})$, localizando-se o ponto 50 na região central e o ponto 100 na margem esquerda. $O$ efluente entra no receptor a $1.100 \mathrm{~m}$ a jusante do ponto zero, conforme é mostrado na FIGURA 1.

As variáveis obtidas foram: riqueza de gêneros do plâncton, $\mathrm{pH}$, temperatura, oxigênio dissolvido, transparência da água, cor e a turbidez da água. As amostras de plâncton foram coletadas com rede horizontal de malha de $50 \mathrm{~m} \mathrm{~m}$, durante 10 minutos. Com exceção das análises de cor, turbidez e DBO, as análises foram realizadas no campo para maior confiabilidade dos resultados. As características do efluente e do rio estão representadas na TABELA 1.

Tabela 1: Características das águas do efluente e do rio.

\begin{tabular}{||l||l||l||l||l||l||l||l|l||}
\hline & pH & Vazão & temp. & OD & DBO & transp. & cor & turbidez \\
\hline \hline efluente & 5.8 & 0.34 & 24 & 2.5 & 42 & 30 & 285 & 140 \\
\hline \hline rio & 7.3 & 157.3 & 19 & 7.1 & 6 & 90 & 35 & 10 \\
\hline
\end{tabular}

\subsection{Análise de superfícies de tendência}

Em um modelo linear simples, se possuído um conjunto de dados nos quais foram medidas duas variáveis " $x_{i}$ " e " $y_{i}$ ", cuja correlação indica um comportamento linear, pode-se ajustar uma reta que melhor se encaixe a esses pares de valores pelo método dos mínimos quadrados. Esse processo permite a construção de uma única reta em relação à qual a somatória das diferenças ao quadrado entre os valores observados menos os correspondentes computados é mínima. Partindo desse caso bidimensional para o modelo linear geral, a analogia é óbvia com o caso tridimensional, onde se deseja 
correlacionar a distribuição de uma variável dependente " $z_{i}$ " em função das coordenadas "x.", no sentido este-oeste, e "y.", no sentido norte-sul. Nessas circunstâncias, deve-se calcular, em vez de uma reta, uma superfície que melhor se adapte ao conjunto de observações, por meio de técnicas matemáticas que fornecerão a melhor superfície mapeável e objetiva. Uma dessas técnicas é a análise de superfícies de tendência. Com a aplicação dessa análise, consegue-se separar dados mapeáveis em duas componentes: uma de natureza regional, representada pela própria superfície, e outra que revela as flutuações locais, representadas pelos valores residuais.

Tendo sido feita a coleta de dados segundo uma rede irregular, o que normalmente acontece em Ecologia, o recurso a ser usado é o do método dos polinômios não-ortogonais, tentando encaixar aos dados, preliminarmente, uma superfície linear, em seguida uma quadrática, e assim por diante. O método usual para o ajustamento aos dados é o da regressão pelos mínimos quadrados. Em seguida, essas superfícies e os respectivos desvios são examinados para que se verifiquem as suas implicações ambientais. Em alguns casos, como em problemas de suavização, o interesse é pelo melhor ajuste aos dados, e procura-se pela superfície de mais alto grau possível. Em outros, como na detecção de anomalias, o que interessa são os resíduos, e calculam-se, então, superfícies de baixo grau com os respectivos mapas de resíduos positivos e negativos.

O modelo para a representação da superfície pelo método dos polinômios não-ortogonais é:

$$
z_{i}(x, z)=\left[a_{0}+a_{1} x_{i}+a_{2} y_{i}+a_{3} x_{i}^{2}+a_{4} x_{i} y_{i}+a_{5} y_{i}^{2}+\mathrm{K}\right]+e_{i}(x, y)
$$

onde $z_{i}{ }^{(x, y)}$ é a variável mapeada em função das coordenadas $x_{i} e y_{i}, \mathrm{e} e_{i}{ }^{(x, y)}$ representa os resíduos, ou seja, a fonte não-sistemática de variação.

A representação de uma superfície linear, por exemplo, é dada por:

$$
z\left(x_{i}, y_{i}\right)=a_{0}+a_{1} x_{i}+a_{2} y_{i}+e_{i}
$$

(1998).

Uma discussão mais detalhada é apresentada em DAVIS (1986) e LANDIM

Os limites da zona de influência do impacto causado pela emissão foram verificados a partir da análise da superfície de tendência com regressão polinomial de primeiro grau e para a detecção de anomalias foram usados os respectivos mapas de resíduos. Para os cálculos e reprodução gráfica dos mapas foi utilizado o "software" Surfer, versão 7 (Golden Software, 1999). 


\subsection{Análise das componentes principais}

Esta análise consiste numa transformação linear de "m" variáveis originais em "m" novas variáveis, de tal modo que a primeira nova variável computada seja responsável pela maior variação possível existente no conjunto de dados, a segunda pela maior variação possível restante e assim por diante até que toda a variação do conjunto tenha sido explicada. É, portanto, uma técnica de transformação de variáveis. Se cada variável medida pode ser considerada como um eixo de variabilidade, estando usualmente correlacionada com outras variáveis, esta análise transforma os dados de tal modo a descrever a mesma variabilidade total existente, com o mesmo número de eixos originais, porém não mais correlacionados entre si. Graficamente pode ser descrita como a rotação de pontos existentes num espaço multidimensional originando eixos, ou componentes principais, que dispostos num espaço a duas dimensões representem variabilidade suficiente que possa indicar algum padrão a ser interpretado.

A análise das componentes principais inicia-se com o cálculo dos autovalores e correspondentes autovetores de uma matriz de variâncias-covariâncias ou de correlações entre variáveis e tal procedimento é conhecido como modo "R". O primeiro autovalor a ser determinado corresponderá à maior porcentagem da variabilidade total presente e assim sucessivamente. Geralmente os dois ou três primeiros autovetores encontrados explicarão a maior parte da variabilidade presente

Os autovetores correspondem às componentes principais e são os resultados do carregamento das variáveis originais em cada um deles. Tais carregamentos podem ser considerados como uma medida da relativa importância de cada variável em relação às componentes principais e os respectivos sinais, se positivos ou negativos, indicam relações diretamente ou inversamente proporcionais.

A matriz de carregamentos de cada variável nas componentes principais ao ser multiplicada pela matriz original de dados fornecera a matriz de contagens (scores) de cada caso em relação às componentes principais. Esses valores poderão então ser dispostos num diagrama de dispersão, em que os eixos são as duas componentes mais importantes, e mostrar o relacionamento entre os casos condicionados pelas variáveis medidas.Ver a respeito REYMENT \& JÖRESKOG (1996)

Os dados físico-químicos e biológicos coletados foram submetidos à técnica multivariada das componentes principais e para os cálculos necessários foi utilizando o programa SYSTAT for WINDOWS, versão 5.01, (SYSTAT, 1993). As componentes principais resultantes sofreram rotações através do método Quartimax, que permitiu um melhor ajuste dos vetores. As configurações espaciais das componentes principais foram interpoladas através do algoritmo DWLS ("distance weight least square"), do módulo 


\section{RESULTADOS E DISCUSSÕES}

A análise da superfície de tendência de primeiro grau mostrou uma tendência de aumento do número de gêneros da margem direita para a esquerda. Esta configuração está ligada à entrada do efluente, que fica na margem direita, como mostrado na FIGURA 1. O mapa de resíduos correspondente a essa superfície indica com clareza a distribuição espacial do número de gêneros antes da entrada do efluente e, principalmente, depois delimitando a pluma resultante dentro da malha de estudo e caracterizada por valores negativos (FIGURA 2). Essa mesma disposição espacial é mostrada em 3D na FIGURA 3.

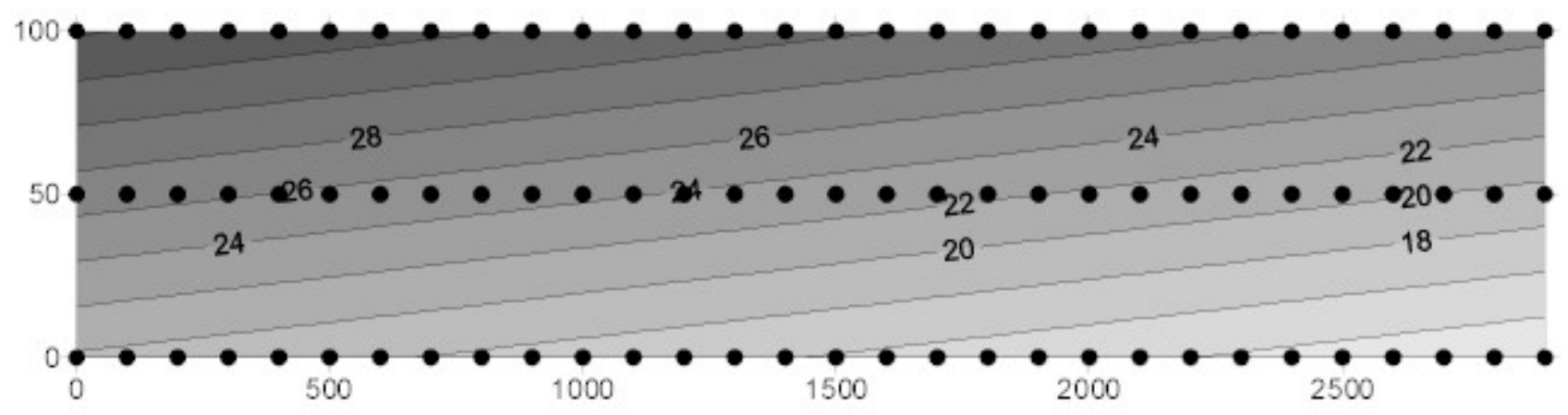

FIGURA 1: Superfície de tendência de grau 1 mostrando a distribuição do numero de gêneros do plâncton diminuindo para a margem direita. Estão assinalados também os locais de coleta $(\cdot)$.

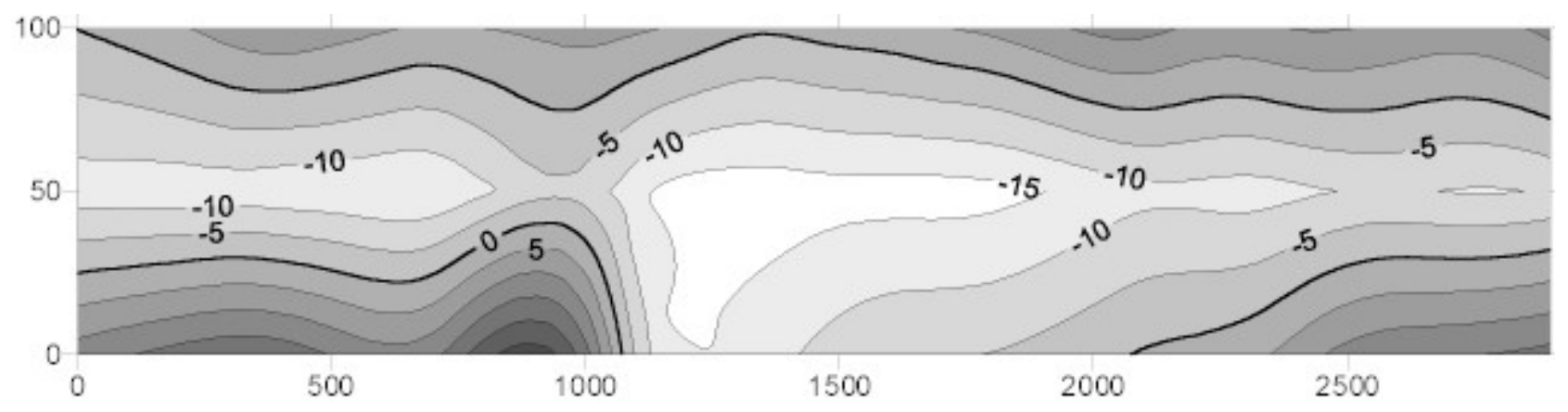

FIGURA 2: Mapa de resíduos da superfície de $1^{\circ}$. grau. A região com valores positivos indica valores para o numero de gêneros do plâncton acima da media regional, representada pela curva 0 , e valores negativos valores abaixo dessa média. 


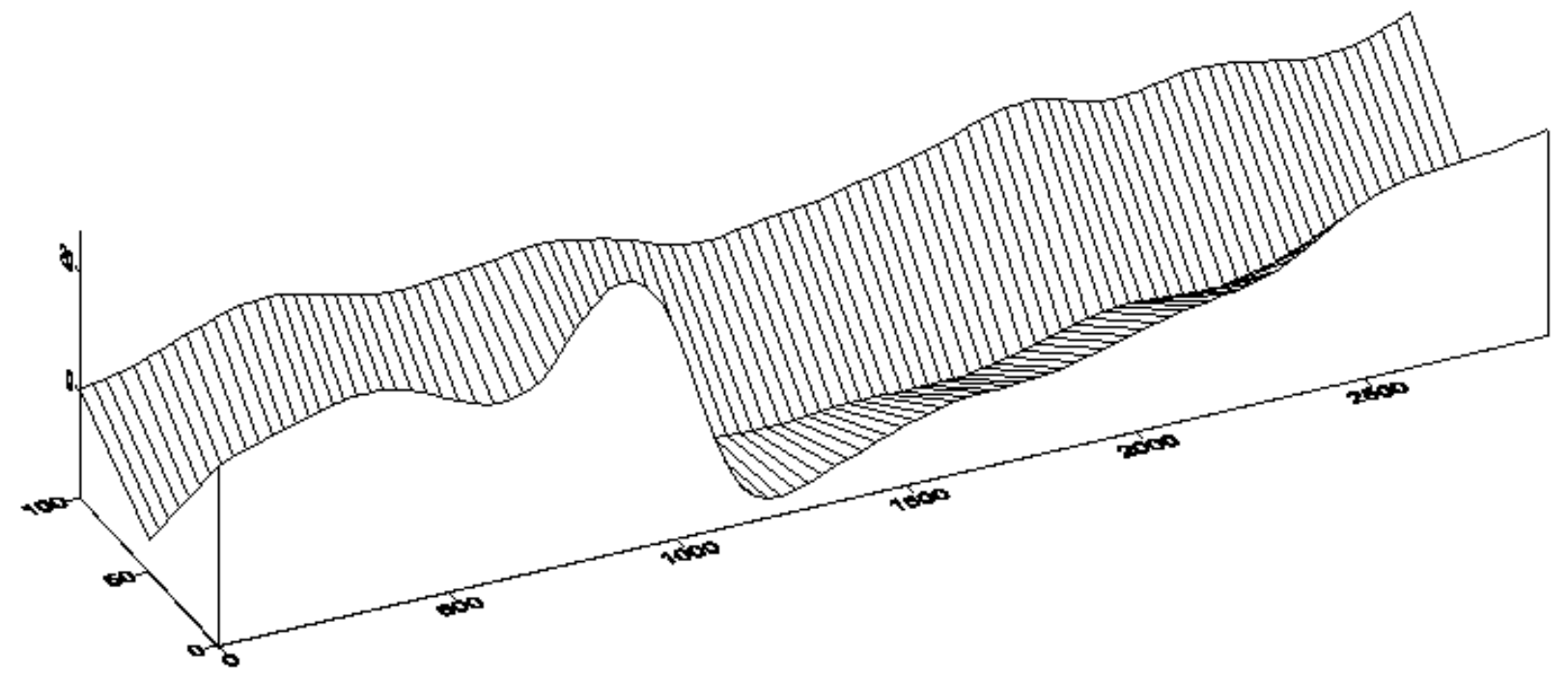

FIGURA 3: Superfície em 3D mostrando a distribuição espacial do numero de gêneros do plâncton com forte queda na entrada do efluente, na altura do valor 1100 .

Como se pode verificar na TABELA 2, resultado da análise das componentes principais, na primeira componente, com uma porcentagem de explicação de $84,64 \%$, as maiores cargas vetoriais, em módulo, ficaram com as variáveis: transparência da água $(0,975)$, OD $(0,969)$, DBO $(-0,984)$ e cor $(-0,969)$. Para a segunda componente as responsáveis pelas maiores cargas foram as variáveis transparência da água $(0,145)$ e número de gêneros do plâncton $(-0,780)$. Devido as maiores cargas na primeira componente obtida serem provenientes das variáveis físico-químicas, esta componente foi interpretada como sendo controlada por fatores abióticos. Como na segunda componente, com uma porcentagem de explicação de $8,37 \%$, a carga mais alta foi devido a variável riqueza de gêneros do plâncton, ela foi considerada como controlada por fatores biológicos. A terceira componente considerada esta controlada pela variável temperatura, com uma porcentagem de explicação muito baixa de 3.941, não foi levada em consideração na discussão.

\begin{tabular}{|l||l||l||l||}
\hline Componentes & I & II & III \\
\hline \hline $\mathrm{N}^{0}$ Gêneros & 0.621 & $\mathbf{- 0 . 7 8 0}$ & 0.066 \\
\hline \hline $\mathrm{pH}$ & 0.957 & 0.019 & -0.033 \\
\hline \hline Temperatura & -0.859 & 0.025 & 0.508 \\
\hline \hline OD & $\mathbf{0 . 9 6 9}$ & 0.031 & 0.130 \\
\hline \hline Profundidade & $\mathbf{0 . 9 7 5}$ & 0.145 & 0.053
\end{tabular}




\begin{tabular}{||l||l||l||l||}
\hline da luz & & & \\
\hline $\mathrm{DBO}_{5}$ & $\mathbf{- 0 . 9 8 4}$ & -0.064 & -0.085 \\
\hline \hline Cor & $\mathbf{- 0 . 9 6 9}$ & -0.129 & -0.015 \\
\hline \hline Turbidez & -0.967 & 0.133 & -0.156 \\
\hline \hline \% de variação & 84.64 & 8.37 & 3.94 \\
\hline
\end{tabular}

TABELA 2 - Cargas das componentes principais sem rotação

A TABELA 3 mostra o resultado após a rotação fatorial. Tal rotação das componentes maximizou, de um modo geral, as cargas das variáveis nos respectivos fatores, como esperado.

\begin{tabular}{|l||l||l||l||}
\hline Componentes & I & II & III \\
\hline \hline $\mathrm{N}^{0}$ Gêneros & 0.531 & $\mathbf{0 . 8 4 5}$ & -0.020 \\
\hline $\mathrm{pH}$ & 0.951 & 0.083 & -0.073 \\
\hline \hline Temperatura & -0.833 & -0.077 & 0.546 \\
\hline \hline OD & $\mathbf{0 . 9 7 0}$ & 0.085 & 0.090 \\
\hline $\begin{array}{l}\text { Profundidade } \\
\text { da luz }\end{array}$ & $\mathbf{0 . 9 8 7}$ & -0.033 & 0.021 \\
\hline \hline DBO 5 & $\mathbf{- 0 . 9 8 7}$ & -0.051 & -0.046 \\
\hline \hline Cor & $\mathbf{- 0 . 9 9 7}$ & 0.021 & 0.018 \\
\hline \hline Turbidez & $\mathbf{- 0 . 9 8 1}$ & 0.014 & -0124 \\
\hline \hline \% de variação & 83.59 & 9.24 & 4.12 \\
\hline
\end{tabular}

TABELA 3 - Cargas das componentes principais rotacionadas (Quartimax)

Na FIGURA 4 estão mostradas as distribuições espaciais dos "scores" das duas principais componentes, após rotação. Os "scores" da primeira componente não 
variam na margem esquerda, ou seja, na parte não afetada, direita e meio do rio antes da entrada do efluente. Após a sua entrada, a componente abiótica começa a variar decaindo a partir da coordenada NS $1100 \mathrm{~m}$, assumindo valores negativos e voltando a crescer a partir da coordenada NS $2000 \mathrm{~m}$. Este comportamento pode ser explicado pelo aumento de $\mathrm{DBO}_{5}$, cor e turbidez com a entrada do efluente e a diminuição do OD e da transparência. A segunda componente varia pouco na margem esquerda decaindo na região do meio do rio. A margem direita começa com cargas positivas, decaindo a partir do ponto de coordenada $1100 \mathrm{~m}$, voltando a crescer depois do ponto de coordenada $2000 \mathrm{~m}$.
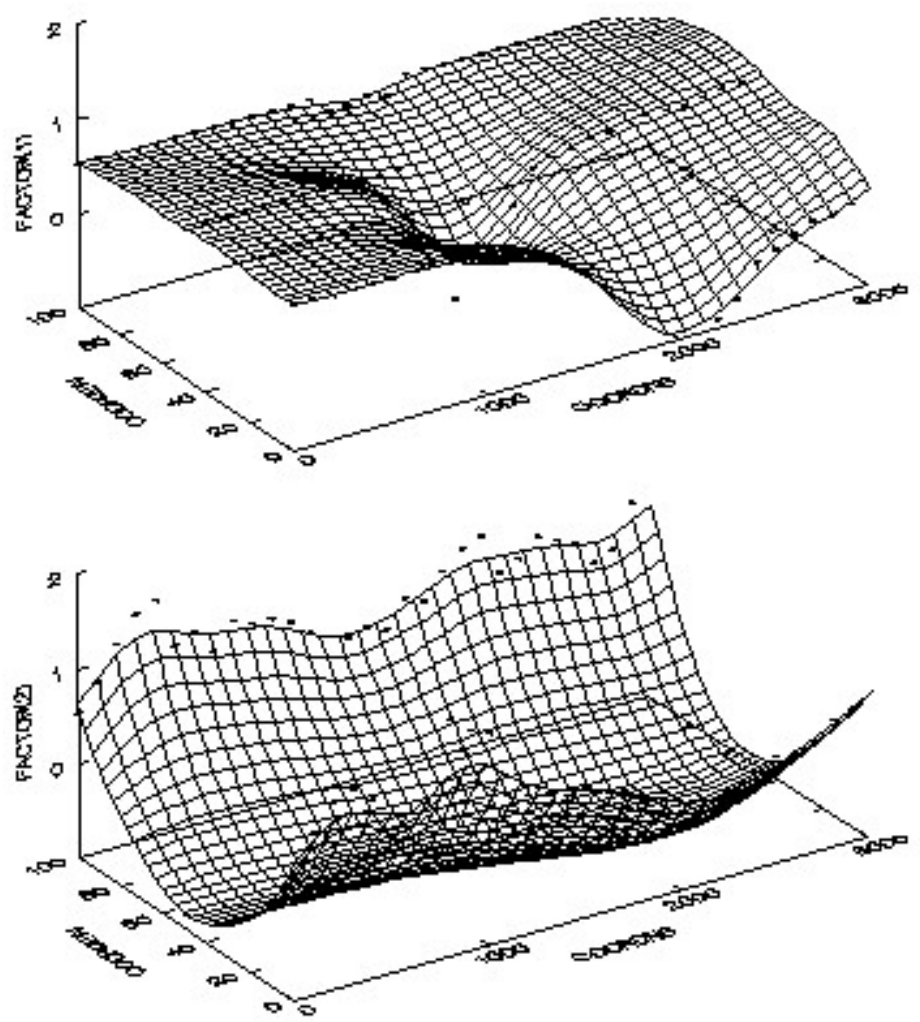

FIGURA 4: Distribuições espaciais das duas componentes principais.

\section{CONCLUSÕES E RECOMENDAÇÕES}

A análise de superfície de tendências mostrou ser uma ferramenta promissora na interpretação dos movimentos das plumas de efluentes no corpo receptor, podendo ser usada como base para um possível monitoramento dessa pluma. Os valores residuais da superfície polinomial de primeiro grau auxiliam a interpretações entre as diferenças locais existentes entre as margens e o meio e ainda a nítida interferência do efluente na riqueza de gêneros do plâncton. Evidentemente que as dimensões encontradas para essa pluma pode variar com a diluição e depuração da água durante o processo de autodepuração. 
A análise das componentes principais forneceu como variáveis mais importantes DBO, OD, transparência da água, cor e numero de gêneros do plâncton, separando duas componentes principais: a primeira, e mais importante, denominada abiótica, controlada por fatores físico-químicos e a segundo biológica, controlada pela riqueza de gêneros planctônicos. Os escores plotados em superfícies espaciais mostraram o impacto do efluente com relação às variáveis estudadas e sua recuperação ao final da malha de amostragem.

Devido ao constante aumento da poluição nas bacias hidrográficas torna-se necessário um controle mais efetivo dos órgãos competentes sobre os recursos hídricos e tal controle pode ser feito, como apresentado neste trabalho, por meio do monitoramento das plumas, utilizando-se da análise espacial conjugada a técnicas estatísticas multivariadas para a interpretação do impacto e sua magnitude nos corpos receptores.

\section{REFERÊNCIAS}

DAVIS, J. C. Statistics and data analysis in geology. 2.ed. New York: John Wiley \& Sons. 1986.

LANDIM, P. M. B. Análise estatística de dados geológicos. São Paulo: Editora da UNESP. 1998.

LEGENDRE, P. Spatial autocorrelation: trouble or new paradigm? Ecology, v. 74, n. 6, p.1659-1673. 1993.

MURGEL-BRANCO, S.. Água : Qualidade, Padrões de Potabilidade e poluição. São Paulo: CETESB. 1974.

REYMENT, R. A.; JÖRESKOG, K. G. Applied Factor Analysis in the Natural Sciences. New York: Cambridge University Press. 1996.

STEINMAN, A. D.; MUlholland, P. J.; PALUMBO, A. V.; DeANGilis, D. L. Lotic ecosystem response to a chlorine disturbance. Ecological Applications, v. 2, n. 4, p. 341-355. 1992. 